\title{
DETECTION OF ABNORMALITIES IN THE SUPERFICIAL ZONE OF CARTILAGE REPAIRED USING A TISSUE ENGINEERED CONSTRUCT DERIVED FROM SYNOVIAL STEM CELLS
}

\author{
Wataru Ando ${ }^{1,2,3}$, Hiromichi Fujie ${ }^{4,5}$, Yu Moriguchi ${ }^{1}$, Ryosuke Nansai ${ }^{4}$, Kazunori Shimomura ${ }^{1}$, David A. Hart ${ }^{2}$,
} Hideki Yoshikawa ${ }^{1}$ and Norimasa Nakamura, ${ }^{1,6,7, *}$

\author{
${ }^{1}$ Department of Orthopaedics, Osaka University Graduate School of Medicine, Suita, Osaka, Japan \\ ${ }^{2} \mathrm{McCaig}$ Institute for Bone and Joint Health, Faculty of Medicine, University of Calgary, Calgary, Alberta, Canada \\ ${ }^{3}$ Department of Orthopaedics, Kansai Rosai Hospital, Amagasaki, Hyogo, Japan \\ ${ }^{4}$ Biomechanics Laboratory, Department of Mechanical Engineering, Kogakuin University, Hachioji, Tokyo, Japan \\ ${ }^{5}$ Biomechanics Laboratory, Faculty of System Design, Tokyo Metropolitan University, Hino, Tokyo, Japan \\ ${ }^{6}$ Center for Advanced Medical Engineering and Informatics, Osaka University, Suita, Osaka, Japan \\ ${ }^{7}$ Institute for Medical Science in Sports, Osaka Health Science University, Osaka, Japan
}

\begin{abstract}
The present study investigated the surface structure and mechanical properties of repair cartilage generated from a tissue engineered construct (TEC) derived from synovial mesenchymal stem cells at six months post-implantation compared to those of uninjured cartilage. TEC-mediated repair tissue was cartilaginous with Safranin O staining, and had comparable macro-scale compressive properties with uninjured cartilage. However, morphological assessments revealed that the superficial zone of TEC-mediated tissue was more fibrocartilage-like, in contrast to the middle or deep zones that were more hyaline cartilage-like with Safranin O staining. Histological scoring of the TECmediated tissue was significantly lower in the superficial zone than in the middle and deep zones. Scanning electron microscopy showed a thick tangential bundle of collagen fibres at the most superficial layer of uninjured cartilage, while no corresponding structure was detected at the surface of TEC-mediated tissue. Immunohistochemical analysis revealed that PRG4 was localised in the superficial area of uninjured cartilage, as well as the TEC-mediated tissue. Friction testing showed that the lubrication properties of the two tissues was similar, however, microindentation analysis revealed that the surface stiffness of the TEC-repair tissue was significantly lower than that of uninjured cartilage. Permeability testing indicated that the TEC-mediated tissue exhibited lower water retaining capacity than did uninjured cartilage, specifically at the superficial zone. Thus, TEC-mediated tissue exhibited compromised mechanical properties at the superficial zone, properties which need improvement in the future for maintenance of long term repair cartilage integrity.
\end{abstract}

Keywords: Cartilage tissue engineering; animal model; image analysis; mechanical properties; mechanical test; microstructure.

*Address for correspondence:

Norimasa Nakamura

Center for Advanced Medical Engineering and Informatics

Osaka University, 2-2 Yamadaoka, Suita

Osaka 565-0871, Japan

Telephone Number: +81-6-6879-3552

FAX Number: +81-6-6879-3559

E-mail: norimasa.nakamura@ohsu.ac.jp

\section{Introduction}

It is widely accepted that injuries to articular cartilage do not usually heal spontaneously due to their avascular surroundings and a variety of approaches have been tested to improve cartilage healing (Buckwalter, 2002; Hunziker, 2002). Among them, stem cell therapy could be a promising option to facilitate regenerative tissue repair. Mesenchymal stem cells (MSCs) have the capability to differentiate into a variety of connective tissue cells including bone, cartilage, tendon, muscle, and adipose tissue (Pittenger et $a l ., 1999)$. These cells may be isolated from various tissues such as bone marrow, skeletal muscle, synovial membrane, adipose tissue, and umbilical cord blood (De Bari et al., 2001; Jankowski et al., 2002; Lee et al., 2003; Wickham et al., 2003). MSCs isolated from synovial membrane may be well suited for cell-based therapies for cartilage because of the relative ease of their harvest and their strong capability for chondrogenic differentiation (De Bari et al., 2001; Sakaguchi et al., 2005; Ando et al., 2007). Recent implantation studies have reported successful repair of cartilage defects using porcine synovial membrane-derived MSCs (Ando et al., 2007; Koga et al., 2008; Koga et al., 2009).

As a potential MSC-based therapeutic method, we have developed a scaffold-free three-dimensional tissueengineered construct (TEC) composed of allogenic MSCs derived from the synovium and extracellular matrices (ECMs) synthesised by the cells (Ando et al., 2007; Ando et al., 2008), and demonstrated the feasibility of the resultant TEC to facilitate cartilage repair in a large animal study (Ando et al., 2007). Following implantation for 6 months, TEC efficiently repaired the chondral defects by developing a cartilage-like tissue without the development of any immunologic reaction, regardless of skeletal maturity (Shimomura et al., 2010). However, more detailed observations revealed that more spindle shaped fibroblast-like cells were dominant in the superficial area of the repair tissue and this was not observed in normal cartilage (Ando et al., 2007; Shimomura et al., 2010). Therefore, it is important to evaluate the quality of repaired tissue in more detail, especially in the superficial zone area.

The function of articular cartilage is to support and distribute loads in joints and to minimise friction between opposing articular surfaces by the maintenance of lubrication. The adequate permeability of tissues is also 
crucial for maintaining the cartilage by transportation of nutrients to chondrocytes in avascular cartilage (Maroudas et al., 1968). In this regard, it is of significance to evaluate the micro-scaled mechanical properties, which are related to compression, lubrication, and permeability of normal and repair articular cartilage. The micro-scaled mechanical properties of in vitro engineered cartilaginous tissues have been investigated (Grad et al., 2012). However, that study did not evaluate the properties of in vivo implanted tissue, and there have been no reports specifically on the microscaled biomechanical properties of the superficial zone of in vivo generated repair cartilage in a large-animal model.

In the present study, we have investigated the detailed structure and micro-mechanical properties of the cartilaginous tissue resulting from treatment with TEC in comparison with those of uninjured articular cartilage in a previously validated porcine model. The findings indicate that the superficial zone of the TEC-mediated repair cartilage is uniquely compromised compared to uninjured cartilage.

\section{Material and Methods}

\section{Isolation and expansion of synovial mesenchymal stem cells (MSCs)}

MSCs were isolated and expanded as previously reported (Ando et al., 2007). Briefly, porcine synovial membranes were obtained aseptically from the knee joints of two four month old male domestic pigs (cross bred animals: Landrace/Yorkshire/Duroc) post-mortem within $12 \mathrm{~h}$ of death in accordance with a protocol approved by the institutional ethics committee. Synovial membrane specimens were taken from the area around the anterior cruciate ligament (ACL) of the knee, rinsed with phosphate buffered saline (PBS), minced meticulously, and digested with $0.4 \%$ collagenase IV (Sigma-Aldrich, St. Louis, MO, USA) in high-glucose Dulbecco's modified Eagle's medium (DMEM; Gibco BRL/Life Technologies, Rockville, MD, USA) for $2 \mathrm{~h}$ at $37^{\circ} \mathrm{C}$. After neutralisation of the collagenase by growth medium containing DMEM supplemented with $10 \%$ foetal bovine serum (FBS; HyClone, Logan, UT, USA) and $1 \%$ Penicillin/Streptomycin (Gibco BRL/Life Technologies), the resulting cells were collected by centrifugation, washed with PBS, resuspended in the growth medium, and plated in culture dishes.

For expansion, the cells were cultured in the growth medium at $37{ }^{\circ} \mathrm{C}$ in a humidified atmosphere of $5 \% \mathrm{CO}_{2}$, with the medium replaced once per week. After 15-28 days of primary culture, when the cells reached confluence, they were washed twice with PBS, harvested by treatment with trypsin-EDTA (0.25\% trypsin and $1 \mathrm{mM}$ EDTA: Gibco BRL/Life Technologies) and then replated at 1:3 dilution for the first subculture. Cell passages were continued in the same manner with 1:3 dilution when they reached confluence. Cells at passages 4 to 7 were used in the present studies. Our previous studies indicated that cells cultured using the above-mentioned procedure were composed of mesenchymal stem cells by cell surface phenotyping (Ando et al., 2007), therefore the cells were defined as MSCs in the present study.

\section{Development of a basic TEC from MSCs}

MSCs were plated on $6 \mathrm{~cm}$ diameter culture dishes at a density of $4.0 \times 10^{5} / \mathrm{cm}^{2}$ in the growth medium with $0.2 \mathrm{mM}$ ascorbic acid 2-phosphate (Asc-2P; Sigma-Aldrich). Within a day, the cells became confluent. After additional culture durations of 7 days, a monolayer complex of the cultured cells and an ECM synthesised by the cells developed, and this was detached from the substratum by application of shear stress at the cell-substratum interface using gentle pipetting. The detached monolayer complex was left in suspension to form a three-dimensional structure by active tissue contraction. This contracted tissue was termed a basic tissue engineered construct (TEC) (Fig. 1ab) (Ando et al., 2007; Ando et al., 2008).

\section{Implantation of basic TEC into porcine chondral defects in vivo}

The resultant TEC were prepared as an allograft without any chondrogenic stimulation. Four-month-old female domestic immature pigs $(n=6)$ were anaesthetised by intramuscular injection of a mixture of ketamine hydrochloride ( $50 \mathrm{mg} / \mathrm{mL}$ and $0.6 \mathrm{~mL} / \mathrm{kg}$ of body weight) and xylazine (20 mg/mL and $0.3 \mathrm{~mL} / \mathrm{kg}$ of body weight) and continuous intravenous injection of propofol (10 mg/ $\mathrm{mL}$ and $8 \mathrm{~mL} / \mathrm{kg} / \mathrm{h}$ ). After a medial parapatella incision, the medial femoral condyles of the both knees were exposed with the knee in deep flexion, and partial thickness chondral defects of $8.5 \mathrm{~mm}$ in diameter and 1.5-2.0 $\mathrm{mm}$ in depth, without penetrating the subchondral bone, were created using an electric router (Proxxon, Niersbach, Germany) and diamond disc grinding (Shofu, Kyoto, Japan). These chondral defects were considered to be comparable with ICRS grade III injury (http://www.cartilage.org/ index.php?pid=223\&lang=1) which is used in a clinical setting. In 4 of the 6 pigs, the basic TEC - which was left in suspension for up to $12 \mathrm{~h}$ until implantation - were implanted into the defect on one side of the knee without suturing (TEC-treated group). On the other side, the defects were left empty (Untreated group). In the other two pigs, the TEC was implanted in the defects on both sides and this group was add to the TEC-treated group (Ando et al., 2007; Shimomura et al., 2010). All animals were immobilised for 7 days with casting and then were allowed free cage activity. They were euthanised under anaesthesia at 6 months after surgery. Each graft site was divided into two parts. One was fixed and used for subsequent paraffin sectioning and histological analysis, and the other was subjected to mechanical testing including compression testing, friction testing, micro indentation testing, and permeability testing. Cylindrical specimens of $4 \mathrm{~mm}$ in diameter and $5 \mathrm{~mm}$ in depth were extracted for the mechanical tests. For comparison, cylindricallyshaped, uninjured cartilage-subchondral bone specimens of identical size were also extracted at a distance from the repair sites (uninjured group). 
(a)

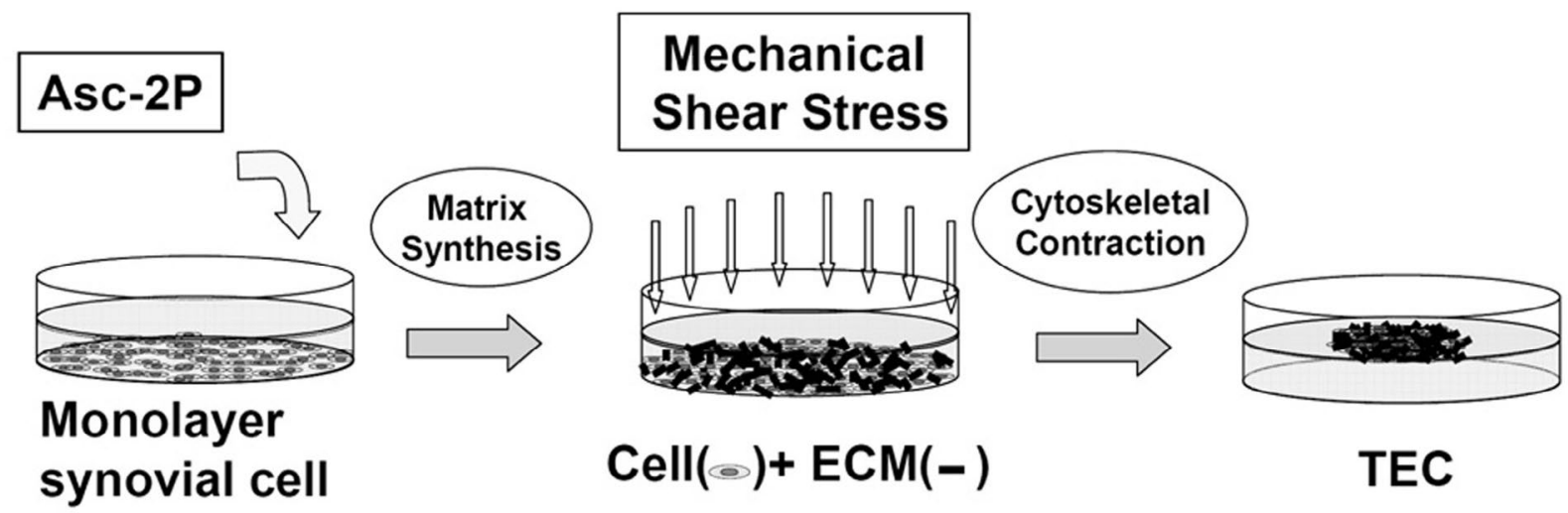

(b)

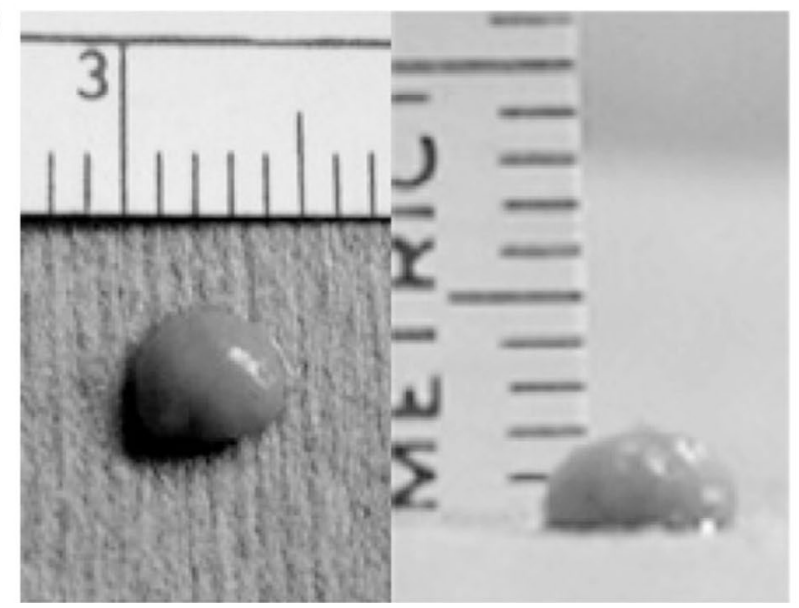

Fig. 1. Scheme of the development of TEC. (a) Schematic drawing of the development of TEC. To enhance extra cellular matrix (ECM) synthesis, ascorbic acid-2-phosphate was added to monolayer cultures of synovial MSCs. After culture durations of 7 days, a monolayer complex of the cultured cells and an ECM synthesised by the cells developed, and this was detached from the substratum by application of shear stress at the cell-substratum interface using gentle pipetting. The detached monolayer complex was left in suspension to form a three-dimensional structure by active tissue contraction. This contracted tissue was termed a basic tissue engineered construct (TEC). (b) Macroscopic view of the TEC, which was integrated to one spherical body. The diameter of this TEC was $5 \mathrm{~mm}$ and the thickness was $2 \mathrm{~mm}$.

Histological and immunohistological analysis

Specimens were fixed with $4 \%$ paraformaldehyde, decalcified with ethylene diamine tetraacetic acid (EDTA), and embedded in paraffin; $4 \mu \mathrm{m}$ sections were stained with haematoxylin and eosin, as well as Safranin O. The repair tissue was divided into 4 parts of $2 \mathrm{~mm}$ width and each area was evaluated using the O'Driscoll scoring system (O’Driscoll, et al., 1988). Each area was also divided into three parts corresponding to the superficial, middle and deep layers and evaluated by several criteria of the O'Driscoll scoring system including cellular morphology, Safranin O staining of the matrix, hypocellularity, and chondrocyte clustering. All scores for each area were averaged.

Picrosirius red was applied to serial sections and observed under polarised light microscopy to assess the collagen fibrils in the superficial layer of the repair tissue.

Serial sections were also subjected to immunohistochemical analysis. A polyclonal antibody (LPN) against proteoglycan 4 (PRG4; lubricin) (Schmidt et al., 2009) was obtained through the courtesy of Dr John Sandy (Rush University, Chicago, IL, USA), and was used as the primary antibody. After the sections were incubated in $0.3 \% \mathrm{H}_{2} \mathrm{O}_{2}$ in $90 \%$ methanol for $30 \mathrm{~min}$ at room temperature to block endogenous peroxidase activity, they were then incubated in $10 \%$ normal goat serum. Next, the antibody LPN was applied to each section, followed by incubation overnight at $4{ }^{\circ} \mathrm{C}$. Detection was then performed using the streptavidin biotin-peroxidase complex technique (Histofine SAB-PO Kit; Nichirei, Tokyo, Japan) before the sections were developed in 3,3-diaminobenzidine tetrahydrochloride (Dojindo Laboratories, Kumamoto, Japan) and counterstained with haematoxylin. Controls included no primary antibody assessments.

\section{Macro-scale quasi-static compression testing}

Macro-scale quasi-static unconfined compression testing was performed for each cylindrical specimen using a custom made compression tester (Katakai et al., 2009). The quasi-static compression was applied to the specimen soaked in the saline solution at a rate of $4 \mu \mathrm{m} / \mathrm{s}$ to determine the bulk stiffness of the specimen in the linear region.

\section{Scanning electron microscopy}

Some cylindrical specimens were longitudinally sliced in the sagittal plane to yield specimens of $0.3 \mu \mathrm{m}$ in thickness, using a microtome. Scanning electron microscopic (SEM) analysis was performed for each section specimen using the method developed by Katakai (Katakai, 2008). After dehydration in $50 \%$ ethanol for $5 \mathrm{~min}$, each specimen 
(a)

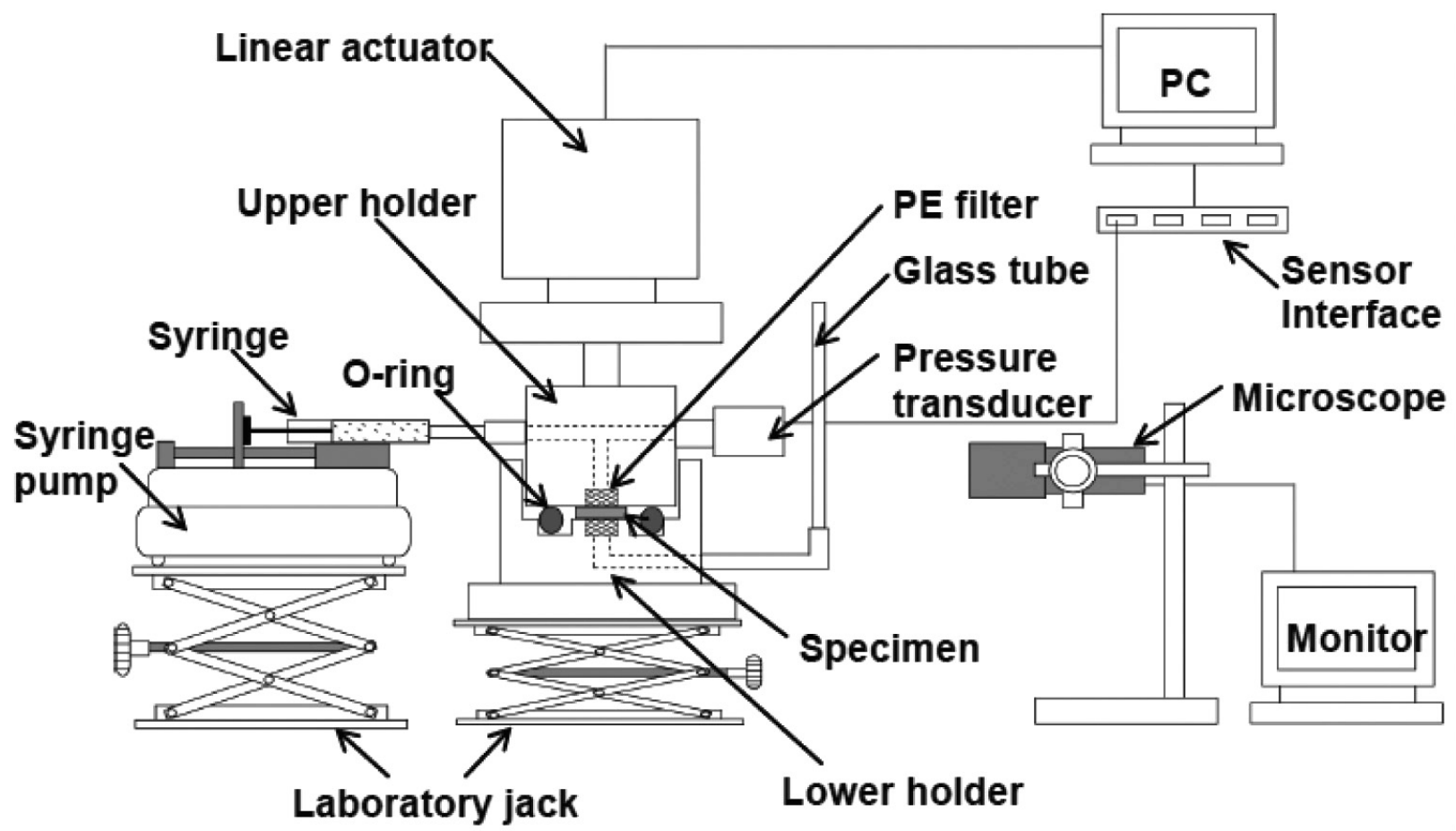

(b)

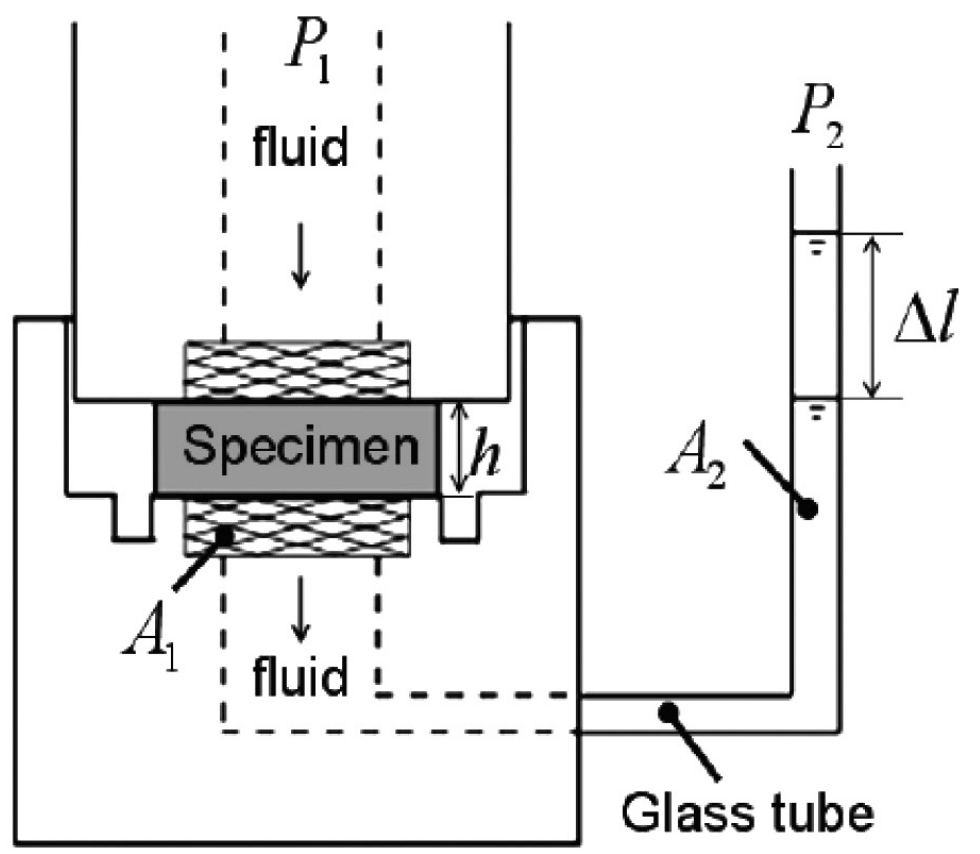

Fig. 2. Scheme of the device used for permeability testing. (a,b) Schematic drawing of the permeability testing apparatus used for assessment of cartilage layer-specimens. Sandwiched layer specimens of an initial thickness of $h_{0}$ was compressed with a strain of $30 \%(\varepsilon=0.3)$ in a saline solution at $37^{\circ} \mathrm{C}$. Under a hydrostatic pressure difference of $70 \mathrm{kPa}\left(P_{1}-P_{2}\right)$, the outflow rate from the specimen $\Delta l / \Delta t$ was measured to determine the permeability of the specimen from the equation shown in the text, where $A_{l}$ represents the cross-sectional area of the specimen, while $A_{2}$ represents the cross-sectional area of the outflow capillary. 
section was then further dehydrated in $70 \%$ ethanol for $5 \mathrm{~min}$ and finally in $100 \%$ ethanol for $5 \mathrm{~min}$. Subsequently, it was fixed on a metal device and immersed in liquid nitrogen. SEM observation was performed for the specimens using a digital microscope (VE-8800, Keyence, Osaka, Japan) at an acceleration voltage of $1.5 \mathrm{kV}$ and a magnification ratio of 15-700.

\section{Atomic Force Microscopy observation and micro- indentation testing}

An atomic force microscope (AFM) (Nanoscope IIIa, Veeco Instruments, Plainview, NY, USA) was used to examine structure-function relationships of uninjured cartilage and repaired tissues in the present study. AFM is a very high-resolution type of scanning probe microscopy, with demonstrated resolution on the order of fractions of a nm. It should be noted that not only geometry but also structural properties such as indentation stiffness can be obtained from uninjured cartilage and repair tissues without any specimen preparation (Kumar et al., 2001; Fujie et al., 2007; Nansai et al., 2011).

Each cylindrical specimen (Uninjured cartilage; $n=11$, TEC-treated tissue; $n=7$, no-treated tissue; $n=4$ ) was mounted on the sample stage of the AFM and soaked in saline solution at room temperature. Surface scanning was performed on the specimen using a contact mode of the AFM at a scan area of $30 \times 30 \mu \mathrm{m}$ and scan rate of $0.3 \mathrm{~Hz}$ using a silicon nitride probe (spring constant: $0.06 \mathrm{~N} / \mathrm{m}$, DNP-S, Veeco Instruments). From the obtained surface images, arithmetic surface roughness $\left(R_{\mathrm{a}}\right)$ was calculated using software installed in the AFM. Finally, a microindentation test was performed three times at 5 sites in each sample at an indentation rate of $5.12 \mu \mathrm{m} / \mathrm{second}$ and the values were averaged to determine the micro-scaled stiffness of the specimen. The distance between the sites assessed was always more than $1 \mathrm{~mm}$. The stiffness of the superficial layer of uninjured cartilage and repair tissue, defined as the slope of the force-indentation curves between 300 and $400 \mathrm{~nm}$ of indentation, were subsequently obtained.

\section{Friction testing}

Reciprocal friction testing was performed for each cylindrical specimen using a friction tester developed in our laboratory (Ando et al., 2007). The specimens were fixed to a probe edge of the tester so that the cartilage/ cartilaginous repair tissue surface was uniformly attached to a glass plate soaked in saline solution at $37^{\circ} \mathrm{C}$. Sixty seconds after the application of vertical load of $1.76 \mathrm{~N}$ $(140 \mathrm{kPa})$, the specimen was subjected to reciprocal friction at a rate of $20 \mathrm{~mm} / \mathrm{s}$ with a stroke of $25 \mathrm{~mm}$. Frictional force was measured with a custom-made cantilever-shaped load transducer with strain gauges having the rated output of $0.36 \mathrm{~N}$ and the non-linearity of $0.04 \%$. Coefficients of friction, defined as the ratio of frictional force to vertical load, were subsequently determined.

\section{Permeability testing}

For the permeability test, the cylindrical specimens used for the previous tests were transversely sliced to surface, middle, and deep layer specimens of approximately
$300 \mu \mathrm{m}$ in thickness, using a microtome. A permeability tester similar to that developed by Weiss et al. (Weiss et al., 2006) was designed (Fig. 2ab). Each specimen of an initial thickness of $h_{0}$ was sandwiched between the top and bottom holders soaked in saline solution and then compressed with a strain of $30 \%(\varepsilon=0.3)$. A syringe pump was manually controlled for $1000 \mathrm{~s}$ so that the hydrostatic pressure difference $P_{1}-P_{2}$ was maintained at $70 \mathrm{kPa}$ with a fluctuation of less than $2 \mathrm{kPa}$. The outflow rate from the specimen $\Delta l / \Delta t$ was measured and the permeability of the specimen, $k$ was determined from the equation shown below based on Darcy's law (Mansour et al., 1976), where $A_{1}$ represents the cross-sectional area of the specimen, while $A_{2}$ represents the cross-sectional area of the outflow capillary.

$$
k=\frac{A_{2} h_{0}(1-\varepsilon) \Delta l}{A_{1}\left(P_{1}-P_{2}\right) \Delta t}
$$

Note that no outflow was allowed from the lateral side of the specimen by means of an O-ring fixed into the tester around the specimen.

\section{Statistical analysis}

The results are presented as mean \pm SD. In microindentation testing, friction testing, and permeability testing, the specimen numbers were 11 for uninjured cartilage, 7 for TEC-treated tissue and 4 for no-treatment repair tissue, and these results were analysed using analysis of variance (ANOVA) with Bonferroni's multiple comparison $t$-test in the STATVIEW version 5.5 software statistics package (SAS Institute, Cary, NC. USA). The results of the superficial thickness and histological scoring were analysed using unpaired $t$-tests and the Mann-Whitney $U$-test, respectively. Significance was set at $p<0.05$.

\section{Results}

\section{Overall histological and biomechanical evaluation of repair cartilage}

When implanted with a TEC, the cartilage defects were repaired with a cartilaginous tissue with positive Safranin $\mathrm{O}$ staining in most of the repair tissue and such staining was also seen throughout the uninjured cartilage (Fig. $3 \mathrm{ab})$. The untreated control defects were partially covered with a fibrous tissue with some evidence of osteoarthritic changes, associated with further loss of cartilage and erosion of subchondral bone (Fig. 3c). By O'Driscoll scoring, the TEC-mediated repair tissue had $62.5 \%$ to $93.8 \%$ values of the mean score of the uninjured cartilage in each category and the overall score was $18.1 \pm 3.7$, which was $75.4 \%$ of that of uninjured cartilage (score: 24 ) (Fig. $3 \mathrm{~d})$. For the histological scoring, all assessment criteria for the TEC-treated group were significantly higher than those for the untreated group, and also lower than that of uninjured group (Fig. 3d). The stress-strain relationships of the uninjured, TEC-treated and untreated specimens in the quasi-static compression test are shown in Fig. 3e. In the quasi-static compression test, the tangent modulus of the TEC-treated cartilage-like tissue was $1438.8 \pm 414.6 \mathrm{kPa}$, 


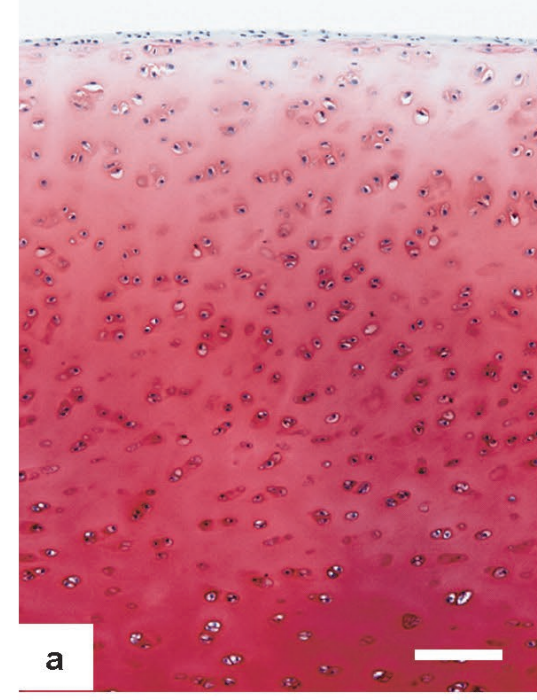

Uninjured

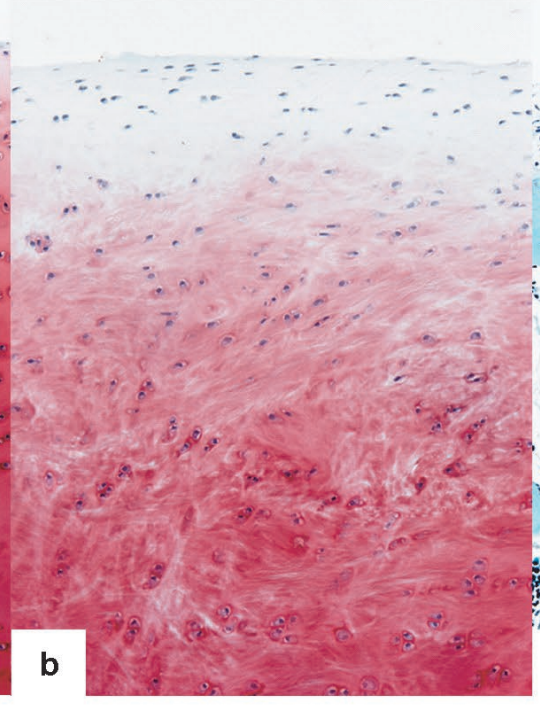

TEC-treated

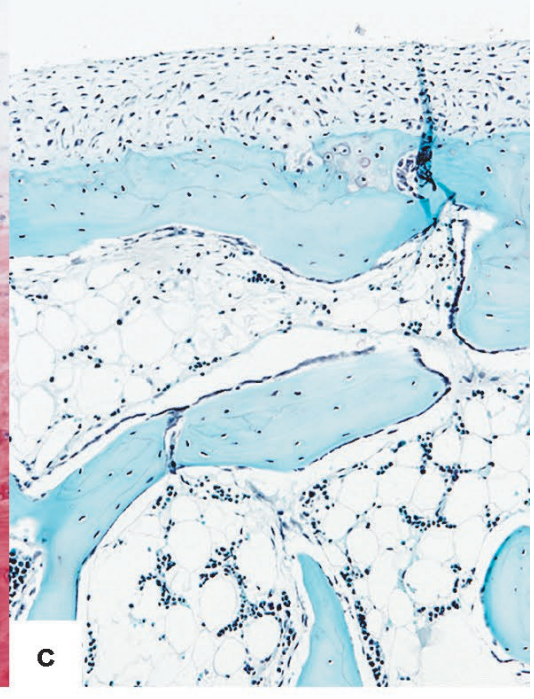

Untreated

(d)

- Uninjured $\square$ TEC-treated $\square$ Untreated

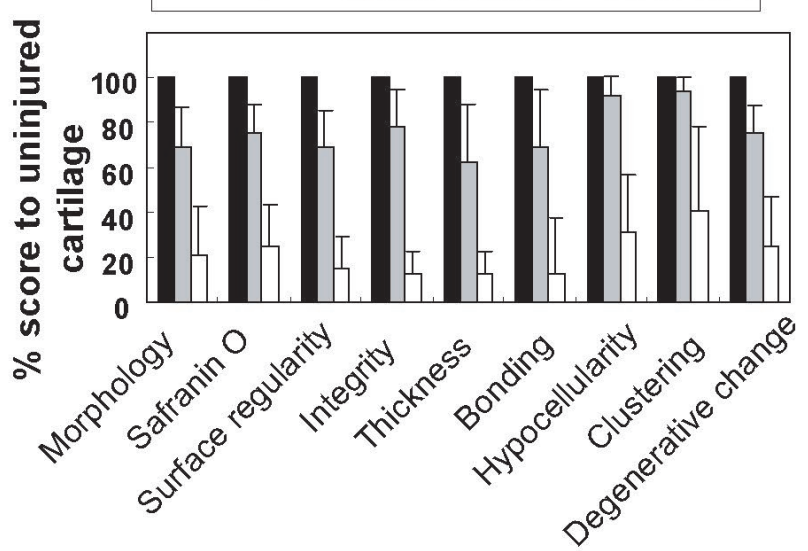

(e)

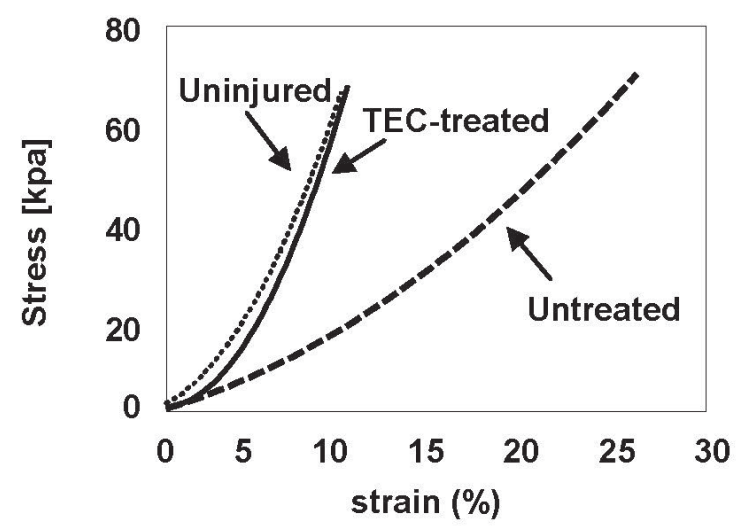

(f)

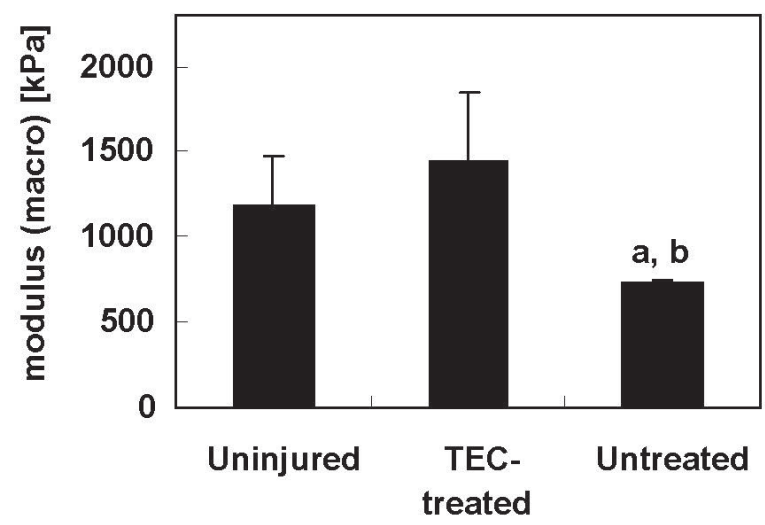

Fig. 3. Overall histological observations and biomechanical evaluation of TEC-mediated repair cartilage. $(\mathbf{a}, \mathbf{b}, \mathbf{c})$ Safranin O staining of porcine uninjured normal articular cartilage (a) and chondral lesions treated with (b) or without (c) TEC at 6 months after implantation. Bar $=100 \mu \mathrm{m}$. (d) O'Driscoll histological and histochemical grading scale of uninjured articular cartilage $(n=12)$, repair tissue treated with (TEC; $n=8)$ and without treatment (Untreated; $n=4$ ) TEC. (e) Typical stress-strain relationships of TEC-treated tissue compared with those of uninjured cartilage and untreated tissue. (f) Tangent modulus of uninjured cartilage $(n=10)$, the chondral lesion in the TEC treated group $(n=6)$ and those in the untreated group $(n=3)$ at compression rate of $4 \mu \mathrm{m} / \mathrm{s}$. a: $p<0.05$, compared to uninjured cartilage. b: $p<0.05$ compared to the TEC treated group. There were no significant differences between the tangent modulus of TEC-mediated repair tissue and that of uninjured cartilage. 
Uninjured

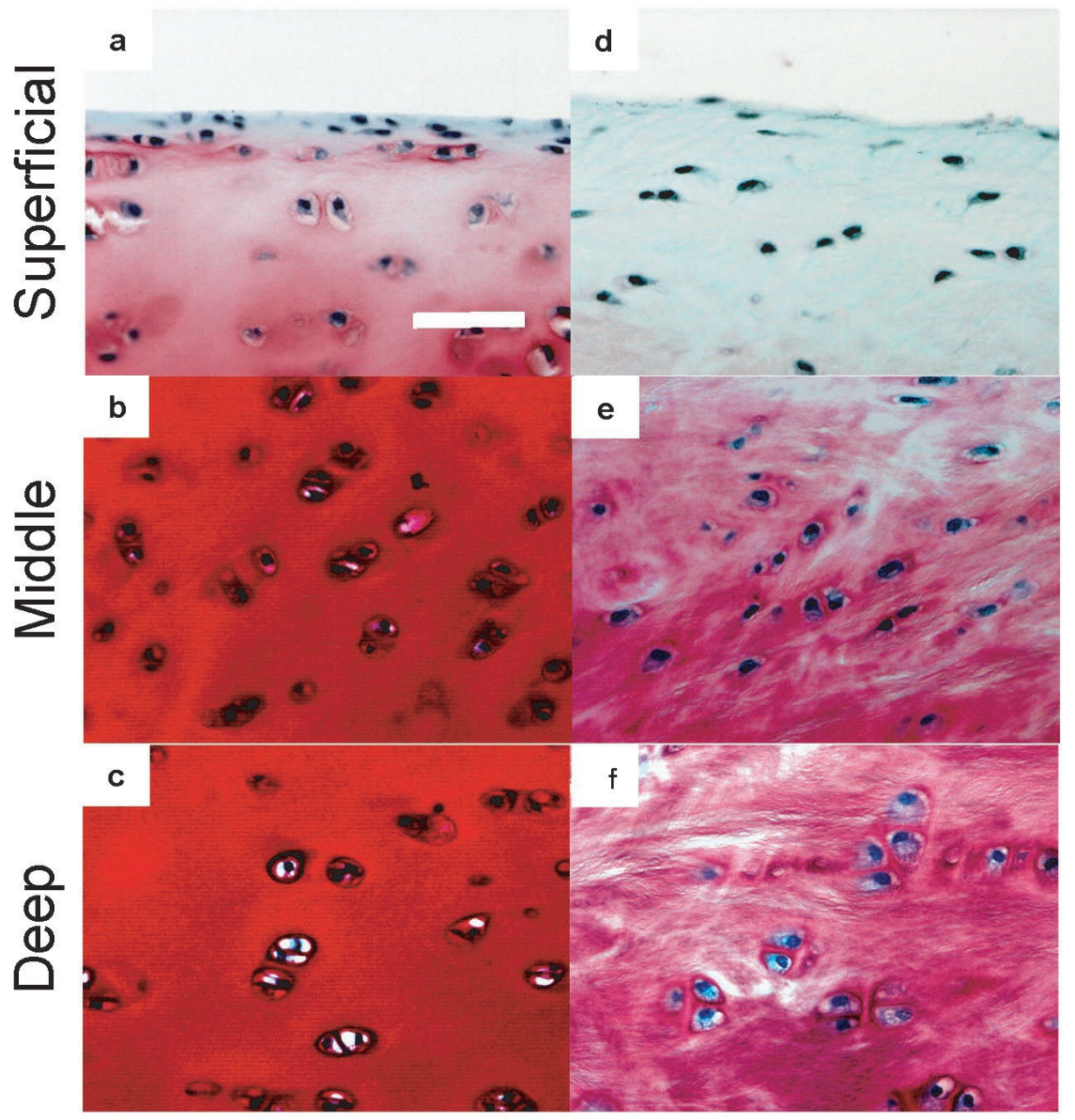

(g)

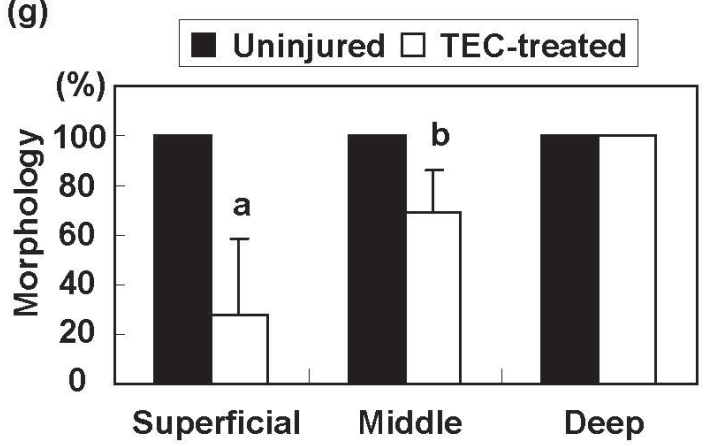

(i)

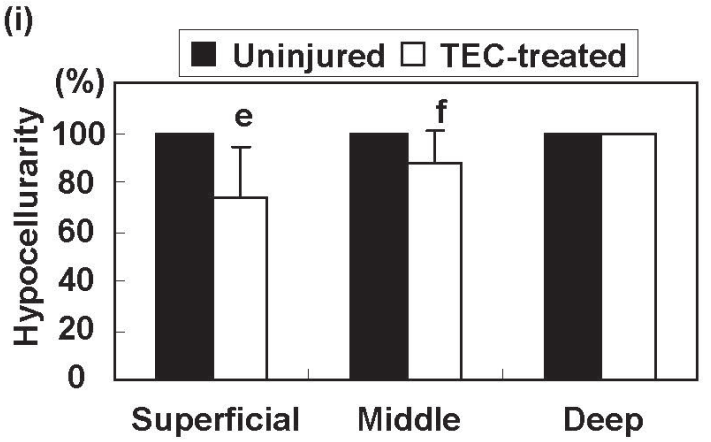

(h)

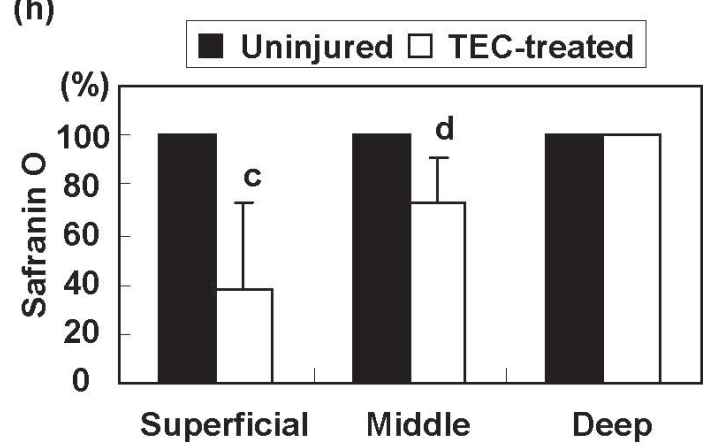

(j)

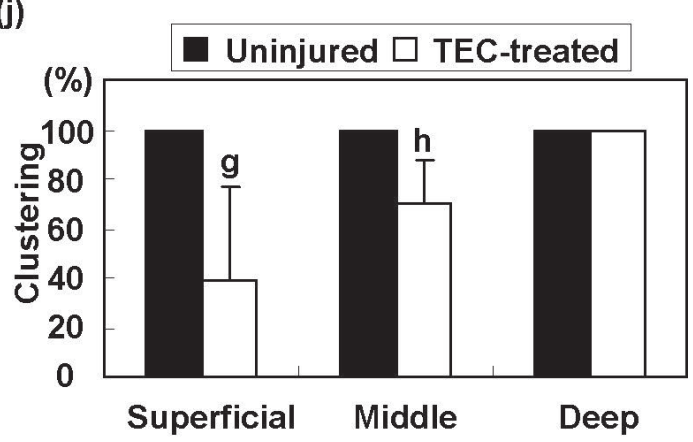

Fig. 4. Zonal histology of uninjured cartilage and the TEC-mediated repair cartilage. (a,b,c) Safranin O staining of superficial (a), middle (b) and deep (c) zone of porcine chondral lesions 6 months after implantation of TECs. Bar $=25 \mu \mathrm{m}$. (d,e,f) Safranin O staining of superficial (d), middle (e), and deep (f) zone of uninjured cartilage. Bar $=25 \mu \mathrm{m}$. (g,h,i,j,j) Zonal histological and histochemical grading scale of uninjured articular cartilage and TECmediated repair tissue $(n=8)$. a,c,g: $p<0.001$, b,d,h; $p<0.01$, e,f; $p<0.05$ compared to the uninjured cartilage. 


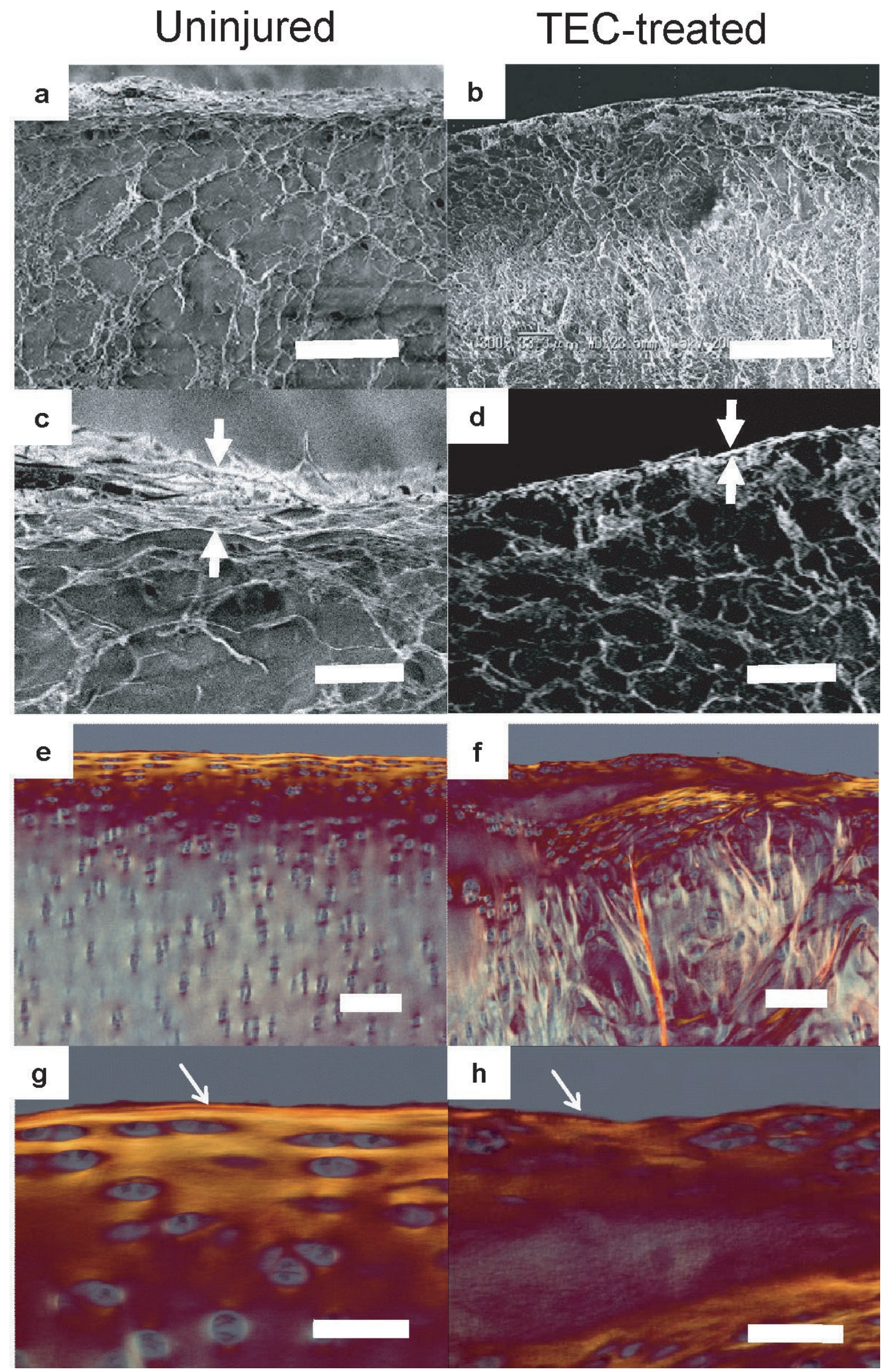

Fig. 5. Surface ultrastructure of repair cartilage. (a,b) Scanning electron microscopic (SEM) view of porcine normal (a) and chondral lesions treated with TEC at 6 months after implantation (b). Bar $=100 \mu \mathrm{m}$. (c,d) Higher magnification SEM view of porcine uninjured cartilage (c) and chondral lesions treated with TEC (d). Bar $=25 \mu \mathrm{m}$. Arrow; the thickness of the superficial layer. (e,f) Polarised microscopic view of porcine uninjured (e) and chondral lesions treated with TEC (f). Bar $=200 \mu \mathrm{m}$. (g,h) Higher magnification polarised microscopic view of porcine uninjured $(\mathrm{g})$ and chondral lesions treated with TEC $(\mathrm{h})$. Bar $=50 \mu \mathrm{m}$. Arrows: one bright thin fibre was observed at the most superficial layer which has been termed the lamina splendens. 


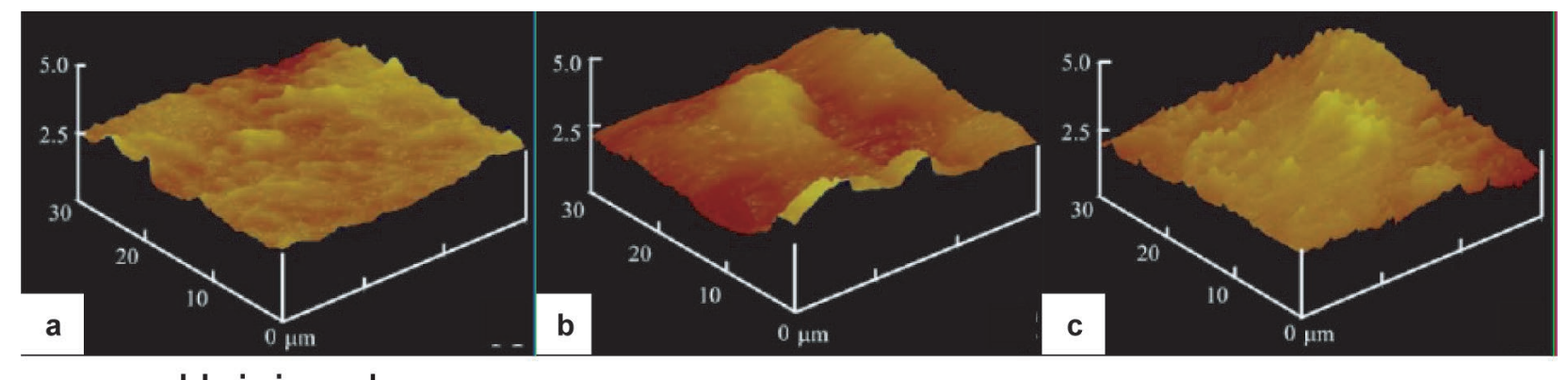

\section{Uninjured}

(d)

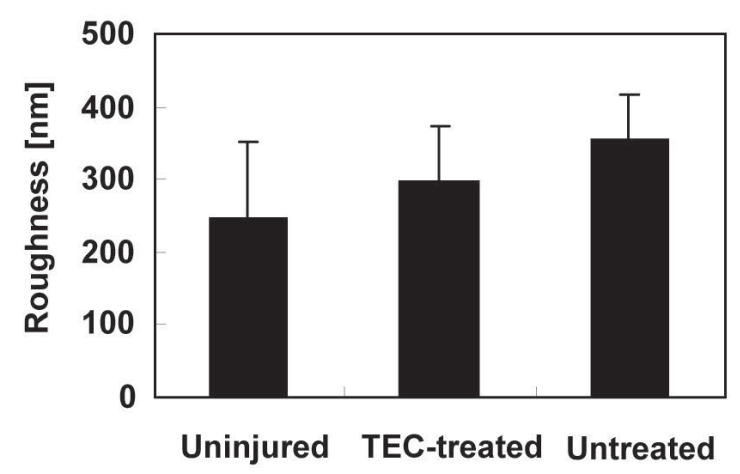

TEC-Treated

Untreated

(e)

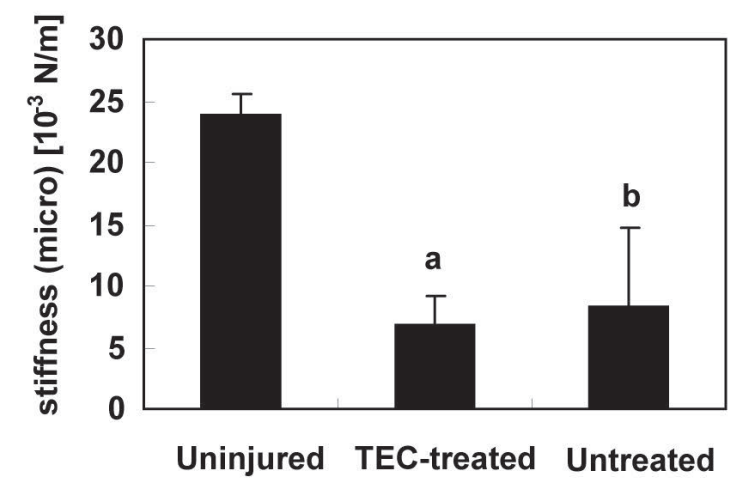

Fig. 6. Surface analysis of uninjured and TEC-mediated repair cartilage. (a,b,c) Atomic force microscopic $(\mathrm{AFM})$ ) view of porcine uninjured cartilage (a) and a chondral lesion treated with (b) or without (c) a TEC at 6 months after implantation. (d) The surface roughness of uninjured cartilage $(n=11)$, the chondral lesions in the TEC treated group $(n=7)$ and that in the untreated group $(n=4)$. (e) The surface stiffness of normal cartilage, the chondral lesions in the TEC treated group and that in the untreated group. a: $p<0.05$, b: $p<0.05$ compared to normal cartilage.

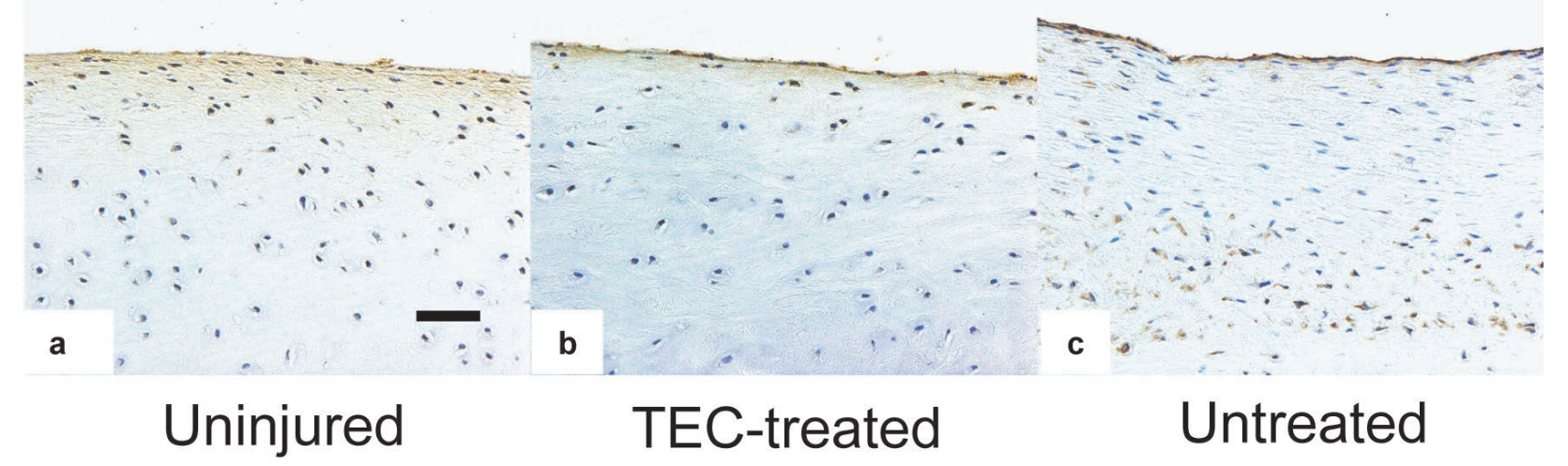

(d)

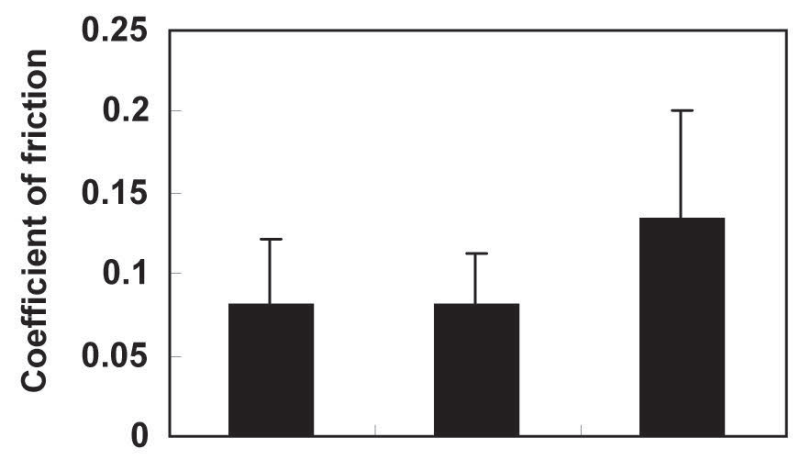

Fig. 7. Localisation of PRG4 in cartilage and lubrication properties. (a,b,c) Lubricin expression at the surface zone of uninjured (a) and chondral lesions treated with (b) or without (c) a TEC. (d) Frictional coefficient of uninjured cartilage $(n=11)$ and chondral lesions in the TEC treated group $(n=7)$ at $60 \mathrm{~s}$ with the application of a compressive force of $1.76 \mathrm{~N}$. There were no significant differences between the frictional coefficients of repair tissue following implantation of a TEC and those of normal cartilage. 
with no significant differences when compared to uninjured cartilage values $(1182.0 \pm 297.0 \mathrm{kPa})$. In contrast, the tangent modulus of the untreated chondral defect tissue was $725.6 \pm 23.9 \mathrm{kPa}$, which was significantly lower than that of the TEC-treated cartilaginous tissue and uninjured cartilage (Fig. 3f).Thus, the TEC treated tissue had overall comparable values in morphology and biomechanical properties with those of uninjured cartilage.

\section{Zonal histology of TEC-mediated repair cartilage}

Zonal histological evaluation of the uninjured articular cartilage at higher magnification revealed that the most superficial area was a layer of fibrocartilage tissue lacking Safranin O staining (Fig. 4a). Most of the cartilage matrix beneath the fibrous layer was stained with Safranin O throughout the zones (Fig. $4 \mathrm{abc}$ ). In the TEC-mediated repair cartilage, fibro-cartilaginous tissue was predominant in the superficial zone of the repair tissue lacking Safranin O staining (Fig. 4d) while most of the repair matrix in the middle and deep zones was composed of cartilaginous matrix with positive Safranin O staining (Fig. 4ef). By O'Driscoll histological scoring, the ratio of the score of the TEC-mediated repair tissue to that of uninjured cartilage was significantly lower in the superficial zone than in the middle and deep zone regarding the category of morphology, Safranin O staining, hypocellularity and chondrocyte clustering (Fig. 4ghij).

\section{Surface ultrastructure of the TEC-mediated repair cartilage}

SEM assessment revealed that there was a dense paralleled fibrous bundle at the most superficial layer of uninjured articular cartilage (Fig. 5a). Conversely, one thin layer covered the surface of the superficial zone of the TECmediated repair=cartilage (Fig. 5b). Higher magnification views revealed that the width of the dense paralleled fibrous bundle was approximately $20 \mu \mathrm{m}$. (Fig. 5c) while the one thin superficial layer of the TEC-mediated repair cartilage was approximately $2 \mu \mathrm{m}$ (Fig. $5 \mathrm{~d}$ ). Picrosirius red staining revealed a bright orange band in the superficial layer of uninjured articular cartilage, of which the thickness was approximately $100-150 \mu \mathrm{m}$ (Fig. 5e). It was notable that a red-coloured thin band with approximately $3 \mu \mathrm{m}$ thickness was observed at the very surface of the orange band zone (Fig. 5g, arrow). Such a red band was not detected at the surface of the TEC-mediated repair tissue (Fig. 5f,h arrow).

\footnotetext{
Surface analysis of TEC-mediated repair cartilage AFM analysis indicated that the surface of the uninjured cartilage consisted of bump-like protrusions of approximately $2 \mu \mathrm{m}$ in height. The surface of the TECmediated and untreated cartilaginous tissues arising after injury exhibited a slightly rougher and a more irregular surface than that detected on uninjured cartilage (Fig. $6 \mathrm{abc})$. The arithmetic surface roughness of the TECmediated cartilaginous tissue was $298 \pm 76.5 \mathrm{~nm}$, which was a value between that of uninjured cartilage $(247 \pm 103$ $\mathrm{nm})$ and the untreated cartilage-like tissue $(354 \pm 61.7 \mathrm{~nm})$, although no significant differences were detected between the three groups (Fig. 6d).
}

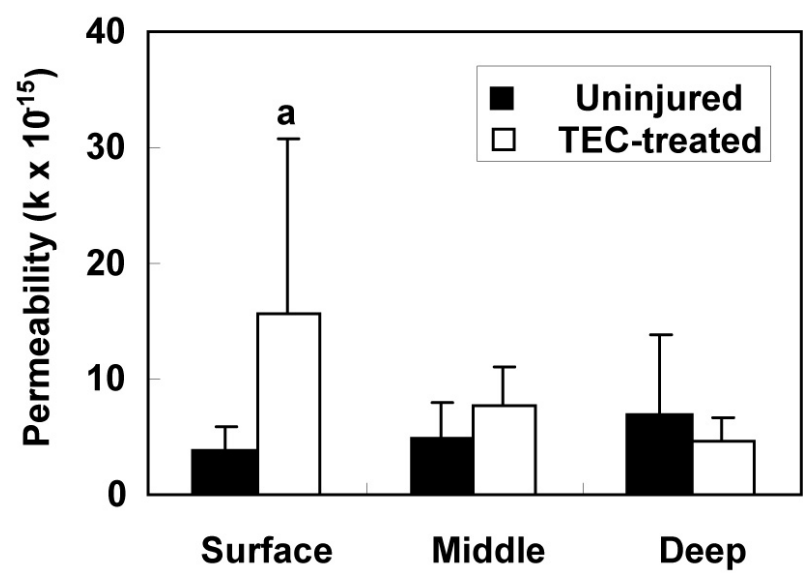

Fig. 8. TEC-mediated cartilage-like repair tissue exhibits low permeability at the superficial zone. Permeability of uninjured cartilage $(n=11)$ and chondral lesions in the TEC treated group $(n=7)$ at the surface, middle and deep zone. a: $p<0.05$, compared to normal cartilage.

Micro-indentation testing showed that the surface stiffness of the TEC-mediated cartilaginous repair tissue was $6.79 \pm 2.30 \times 10^{-3} \mathrm{~N} / \mathrm{m}$ and the untreated cartilaginous tissues was $8.21 \pm 6.51 \times 10^{-3} \mathrm{~N} / \mathrm{m}$, which were both significantly lower than values for uninjured cartilage $\left(23.8 \pm 1.70 \times 10^{-3} \mathrm{~N} / \mathrm{m}\right)$ (Fig. 6e).

\section{Localisation of PRG4 in TEC-mediated repair cartilage and lubrication properties}

The proteoglycan 4 (PRG4) (lubricin) is considered to be the major protein responsible for the lubrication of articular cartilage (Swann et al., 1977; Jay, 1992). PRG4 was localised to the surface of both uninjured and TECmediated repair cartilage, as well as the untreated repair tissue (Fig. 7abc). Friction testing indicated that the coefficient of friction for the TEC-mediated tissue was $0.081 \pm 0.033$, with no significant differences observed between those of uninjured cartilage $(0.081 \pm 0.041)$ and the untreated repair tissue $(0.133 \pm 0.067)$ (Fig. $7 b)$. The latter finding is likely due to the wide variability observed in the samples from the untreated group.

\section{Permeability of the TEC-mediated repair cartilage}

Permeability testing showed that the permeability of the TEC-mediated cartilage-like tissue was significantly higher than that of normal cartilage $\left(18.6 \pm 15.7 \times 10^{-15} \mathrm{~m}^{4} / \mathrm{Ns}\right.$ vs. $3.86 \pm 2.00 \mathrm{~nm} \times 10^{-15} \mathrm{~m}^{4} / \mathrm{Ns}$ ) at the superficial zone, while there were no significant differences detected at the middle $\left(6.63 \pm 3.26 \times 10^{-15} \mathrm{~m}^{4} / \mathrm{Ns}\right.$ vs. $4.74 \pm 3.13 \mathrm{~nm} \times 10^{-}$ $\left.{ }^{15} \mathrm{~m}^{4} / \mathrm{Ns}\right)$ and the deep zones $\left(4.67 \pm 2.00 \times 10^{-15} \mathrm{~m}^{4} / \mathrm{Ns}\right.$ vs. $7.02 \pm 6.73 \mathrm{~nm} \times 10^{-15} \mathrm{~m}^{4} / \mathrm{Ns}$ ) (Fig. 8). These results indicated that the middle to deep zones of the TECmediated repair cartilage had a fluid retention capacity similar to uninjured cartilage, while the superficial zone was more permeable than uninjured cartilage. 


\section{Discussion}

We have previously demonstrated the feasibility of the MSC-derived TEC approach for cartilage repair and showed the equivalent overall morphology and macroscale compressive properties of TEC-mediated repair cartilage compared to normal cartilage (Ando et al., 2007; Katakai et al., 2009). However, we also pointed out the morphological abnormality in the superficial area of the TEC-mediated repair cartilage, with the predominance of fibro-cartilaginous tissue. The introduction of micro-scale biomechanical analysis along with detailed ultrastructural observations has enabled a more precise evaluation of zonespecific structure and function between normal and TECmediated repair cartilage. The present study specifically focused on the superficial zone of the repair cartilage and elucidated a number of unique characteristics of the tissue, morphologically and biomechanically. Grad et al. recently investigated the surface micro-scaled biomechanical properties of in vitro engineered cartilaginous tissues (Grad et al., 2012). However, to our knowledge, the present study is the first demonstration of these unique functional abnormalities in the superficial zone of repair cartilage following implantation in a large animal model.

Morphologically, the combination of SEM with picrosirius red staining under polarised microscopy clearly demonstrated the difference in the surface structure of uninjured cartilage and the TEC-mediated repair tissue. SEM detected the dense paralleled fibrous bundle with the thickness of approximately $20 \mu \mathrm{m}$ at the most superficial layer of uninjured articular cartilage. Interestingly, picrosirius red staining of the corresponding area showed the presence of a bright orange band, with approximately 100-150 $\mu \mathrm{m}$ thickness, aligned parallel with the surface of uninjured articular cartilage. Previous studies suggested that the thickness of the superficial tangential zone of articular cartilage has 10-20\% of the thickness of the whole cartilage (Mow et al. 1990) and the average thickness of porcine femoral articular cartilage is reported to be about $1 \mathrm{~mm}$ at 11 months of age, which corresponds to the period at the tissue sampling in the present study (10-11 months old) (Rieppo et al.. 2009). Thus, the thickness of the superficial tangential zone could be expected to be approximately $100-200 \mu \mathrm{m}$. The similarity in the thickness suggests that the surface orange band detected by picrosirius red staining may correspond to the superficial tangential zone and that the dense tangential fibrous band detected by SEM, which has less than $20 \%$ of the thickness of the orange band, might be the superficial specialised structure involved in the superficial tangential zone. Notably, a bright red thin band with the thickness of $3 \mu \mathrm{m}$ was observed at the very surface of uninjured cartilage. MacConaill first reported a thin bright line at the articular surface which consisted of parallel aligned fibres and termed it the lamina splendens (MacConaill, 1951). The width of the lamina splendens was reported to be 3.2-5.2 $\mu \mathrm{m}$ (Dunham, et al., 1988) and 4-8 $\mu \mathrm{m}$ (Teshima et al., 1995) in canine tibial plateau and human femoral head, respectively. Based on the similarity in the thickness, the red bright band presumably corresponds to the lamina splendens. On the other hand, SEM showed a thin fibre with the thickness of $3 \mu \mathrm{m}$ at the surface of the TEC-treated cartilaginous tissues. However, picrosirius red staining did not show such a bright red or orange band at the tissue surface. Therefore, it is likely that the lamina splendens, or the structure of the superficial tangential zone, was not restored in the TECtreated cartilaginous repair tissue. Significantly, inferior O'Driscoll scores in the TEC-mediated repair cartilaginous tissue at the superficial zone level may also be a reflection of the loss of the superficial structures. Thus, the lack of the lamina splendens coupled with the altered superficial tangential structure at the surface of the TEC-mediated repair cartilaginous tissue could be the most significant morphological finding in the present study.

The lamina splendens, together with the superficial tangential zone, is regarded as playing various important roles in maintaining the mechanical response of articular cartilage to load (Thambyah et al., 2007, Hollander et al., 2010), joint physiology - such as withstanding extrinsic compression and intrinsic swelling pressure and facilitating joint lubrication (Teshima et al., 1995). Therefore, the lack of these superficial structures could lead to a functional insufficiency at the superficial zone of the repaired cartilage in many properties, such as surface roughness, stiffness, lubrication and water retaining potential to control intrinsic swelling pressure. This may compromise the long term functionality of the repair tissue unless it continues to improve with time post-implantation.

In order to assess the potential functional insufficiency of the superficial zone of repair-cartilage, the atomic force microscopy (AFM) approach was employed. AFM has been reported to allow evaluation of the structuremechanical property relationships at the surface of articular cartilage at the $\mu \mathrm{m}$ and nm scales (Stolz et al., 2004; Hsieh et al., 2008) and thus, to examine surface roughness and stiffness of the repair cartilage. There were no significant differences in the surface roughness between the TECmediated repair-cartilage and uninjured cartilage, while significantly lower micro-scale stiffness was detected in the TEC-mediated repair cartilage than in the uninjured cartilage. This result was in contrast with those of previous macro-scale compression assessments, where no significant differences between TEC-mediated repair cartilage and the uninjured cartilage were detected. Such findings indicate the lack of sensitivity of the macro approach and the importance of micro-scaled mechanical testing.

The proteoglycan 4 (PRG4) (lubricin) is a mucinous glycoprotein expressed in cartilage and one which is believed to play an important role in the boundary lubrication of articular cartilage (Swann et al., 1977; Jay et al., 1992). Therefore, expression and localisation of this molecule may estimate the lubrication properties of the TEC-mediated repair cartilage. In the present study, we demonstrated that PRG4 was similarly localised to the superficial zone of the TEC-mediated repair cartilage and in normal uninjured cartilage. In accordance with the similar localisation pattern of PRG4, there were no significant differences in the coefficient of friction between the TEC-mediated repair cartilage and the uninjured cartilage. We previously reported that the coefficient of friction of 
the TEC-mediated repair cartilage was not significantly different from that of normal cartilage (Ando et al., 2007). However, the results were obtained immediately after loading of the specimens, when the lubrication mode was thought to be a combination of hydrodynamic lubrication and boundary lubrication. Therefore, in the previous study, there might have been no clear effect of loading duration on the friction in which the boundary lubrication becomes dominant (Pickard et al., 1998). In the present study, in order to eliminate that potential problem, we started the examination after $60 \mathrm{~s}$ of loading, and again obtained similar results. Taken together, the structural abnormality in the superficial zone of repair cartilage did not likely affect the surface localisation of PRG4 or the boundary lubrication properties of the repair cartilage.

Finally, we investigated the permeability (inverse relation to water retention capacity) of the repair cartilage. This capacity is considered essential to influence the crucial function of articular cartilage to control intrinsic swelling pressure (Mansour et al., 1976). Interestingly, the TECmediated repair cartilage exhibited permeability similar to the uninjured cartilage at the level of the middle and deep zones, while higher permeability was detected in the repair cartilage at the surface/superficial zone. The permeability of normal cartilage has been reported to increase as one assesses deeper zones (Muir et al., 1970), while the tendency of the TEC-mediated cartilaginous repair tissue was shown to be the opposite in the present studies. The present results clearly indicated that the superficial zone of the TEC-mediated repair cartilage exhibited significantly lower water retaining capacity. This is the first clear demonstration of a novel functional insufficiency involved in the superficial zone of the TEC-mediated repair cartilage, an insufficiency which could be closely related to the superficial structural abnormalities also detected in the present studies. A future detailed analysis in the structure and composition of the superficial tangential zone will be required to identify the key molecule or structure which is responsible for the water retaining capacity of normal uninjured cartilage and why the TEC-mediated repair tissue is compromised in this regard.

Despite the differences in the structure and permeability between the superficial zone of the uninjured and the TEC-mediated repair cartilage, no statistically significant differences were observed in the coefficient of friction. The coefficient of friction is known to strongly depend on interstitial fluid pressurisation (Ateshian et al., 2009). Given the higher permeability of the superficial zone, a diminished ability to maintain fluid load support in the TEC group was expected, translating into an increase in the measured coefficient of friction. This, however, was not observed in the present study. There are likely two points contributing to such discrepancy. First, the coefficient of friction was measured $60 \mathrm{~s}$ after the application of normal load, when the boundary lubrication became dominant. At that moment, the boundary film on the cartilage surface, such as lipid and protein, likely played a major role in lubrication and thus, the effect of interstitial fluid pressure may have been diminished. Secondly, even if the effect of interstitial fluid pressure remained, the modulus of the repair cartilage became softer than normal cartilage while the permeability became greater at the surface.

One of the limitations of this study was that it followed the results up to only 6 months after surgery and it is not clear whether the findings observed in the present study would continue over the long-term, or improve with time post-implantation. Specifically, there may be the possibility for the further improvement of the structure of the superficial tangential zone and of the corresponding mechanical properties of the TEC-mediated repair tissue. Longer follow up studies will be required. The use of immature pigs might be another concern. However, we had previously confirmed that skeletal maturity does not affect the quality of the TEC-mediated repair cartilage, using the same surgical model (Shimomura et al., 2010), and thus the use of immature animals has been somewhat validated. Another limitation was using uninjured specimens from the same condyle which had undergone surgery. Even "uninjured" articular surfaces may have been influenced by inflammatory responses following implantation, as well as the mechanical effect of incongruence created by those chondral defects. Therefore, these specimens might not be the most perfect "normal" control. However, extensive morphological analyses showed that the uninjured cartilage showed exactly the features as normal cartilage. Finally, we failed to directly prove the structure-function relationship in the articular surface due to the missing sample to sample correspondence between the histological scoring and biomechanical testing, and, therefore, direct statistical correlations could not be calculated. However, the significant inferiority in histological scores of the superficial zone of the TEC-mediated repair cartilage compared to the uninjured cartilage, as well as the significantly inferior biomechanical properties - including micro-scale stiffness and permeability in the superficial zone of the TEC-treated tissue to the uninjured cartilage - strongly suggest correlations between the microscopic structural features, with the altered micro-biomechanical properties in the articular surface, do exist.

This study revealed unique structural abnormalities in the superficial zone of the TEC-mediated cartilaginous repair tissue. Although not discussed widely, a critical review of publications focused on cell-based cartilage repair suggests that the predominance of fibro-cartilaginous tissue at the superficial zone of the repair cartilage was likely not peculiar to the present study, but was rather commonly observed in cell-based cartilage repair using autologous chondrocytes and MSCs (Knutsen et al., 2004; Saris et al., 2008; Gooding et al., 2006; Nejadnik et al., 2010). It is our speculation that it is not likely to develop functional articular surface structure by the implantation of a biomechanically immature implant without any followup treatment. In this regard, the restoration of the lamina splendens and the superficial tangential zone, which is the specialised membrane-like structure composed of densely packed collagen fibrils, should be an important target to focus on for the improvement of cartilage repair quality as the field moves towards tissue regeneration. 


\section{Conclusions}

Cartilage defects, repaired by implantation of a scaffoldfree tissue engineered construct (TEC) derived from synovial mesenchymal stem cells, are cartilaginous tissue which exhibited macro-scale compressive properties similar to uninjured cartilage. However, the TEC-mediated repair cartilage lacks the lamina splendens, as well as the superficial tangential zone, and exhibits inferior microscaled mechanical properties such as surface stiffness and water retaining capacity. Further improvement of these surface structures will be required to optimise cartilage regeneration.

\section{Acknowledgements}

We thank Dr. Daisuke Katakai, Miss Machiko Imura and Takuya Suzuki for assistance with the AFM and Micro-indentation testing as well as Dr. Kosuke Tateishi for animal surgery. We also appreciate the generosity of Dr John Sandy (Rush University, Chicago, IL, USA) for providing the antibody against PRG4 The present study was financially supported in part by the NEDO (Threedimensional Complex Organ Structure project) (060019040), and the MEXT (BERC, Kogakuin University).

\section{References}

Ando W, Tateishi K, Hart DA, Katakai D, Tanaka,Y, Nakata K, Hashimoto J, Fujie H, Shino K, Yoshikawa $\mathrm{H}$, Nakamura N (2007) Cartilage repair using an in vitro generated scaffold-free tissue-engineered construct derived from porcine synovial mesenchymal stem cells. Biomaterials 28: 5462-5470.

Ando W, Tateishi K, Katakai D, Hart DA, Higuchi C, Nakata K, Hashimoto J, Fujie H, Shino K, Yoshikawa $\mathrm{H}$, Nakamura N (2008) In vitro generation of a scaffoldfree tissue-engineered construct (TEC) derived from human synovial mesenchymal stem cells: biological and mechanical properties and further chondrogenic potential. Tissue Eng Part A 14: 2041-2049.

Ateshian GA (2009) The role of interstitial fluid pressurization in articular cartilage lubrication. J Biomech 42: 1163-1176.

Buckwalter JA (2002) Articular cartilage injuries. Clin Orthop Relat Res 402: 21-37.

De Bari C, Dell'Accio F, Tylzanowski P, Luyten FP (2001) Multipotent mesenchymal stem cells from adult human synovial membrane. Arthritis Rheum 44: 19281942.

Dunham J, Shackleton DR, Billingham ME, Bitensky L, Chayen J, Muir IH (1988) A reappraisal of the structure of normal canine articular cartilage. J Anat 157: 89-99.

Fujie H, Suzuki T, Katakai D, Ando W, Nakamura N (2007) Atomic force microscopic study on microcompressive properties of cartilage repaired with scaffoldfree three-dimensional bioengineered tissues (3DSTs), Proc 6th Comb Meet Orthopaed Res Soc, 37.
Gooding CR, Bartlett W, Bentley G, Skinner JA, Carrington R, Flanagan A (2006) A prospective, randomised study comparing two techniques of autologous chondrocyte_implantation for osteochondral defects in the knee: Periosteum covered versus type I/III collagen covered. Knee 13: 203-210.

Grad S, Loparic M, Peter R, Stolz M, Aebi U, Alini M (2012) Sliding motion modulates stiffness and friction coefficient at the surface of tissue engineered cartilage. Osteoarthritis Cartilage, in press.

Hollander AP, Dickinson SC, Kafienah W (2010) Stem cells and cartilage development: complexities of a simple tissue. Stem Cells 28: 1992-1996.

Hsieh CH, Lin YH, Lin S, Tsai-Wu JJ, Herbert Wu CH, Jiang CC (2008) Surface ultrastructure and mechanical property of human chondrocyte revealed by atomic force microscopy. Osteoarthritis Cartilage 16: 480-488.

Hunziker EB (2002) Articular cartilage repair: basic science and clinical progress. A review of the current status and prospects. Osteoarthritis Cartilage 10: 432-463.

Jankowski RJ, Deasy BM, Huard J (2002) Musclederived stem cells. Gene Ther 9: 642-647.

Jay GD (1992) Characterization of a bovine synovial fluid lubricating factor. I. Chemical, surface activity and lubricating properties. Connect Tissue Res 28: 71-88.

Katakai D (2008) Biomechanics of cartilage repair using mesenchymal stem cells. Ph.D. Dissertation (Kogakuin University).

Katakai D, Imura M, Ando W, Tateishi K, Yoshikawa H, Nakamura N Fujie H (2009) Compressive properties of cartilage-like tissues repaired in vivo with scaffold-free, tissue engineered constructs. Clin Biomechanics 24: 110116.

Knutsen G, Engebretsen L, Ludvigsen TC, Drogset JO, Grøntvedt T, Solheim E, Strand T, Roberts S, Isaksen V, Johansen O (2004) Autologous chondrocyte implantation compared with microfracture in the knee. A randomized trial. J Bone Joint Surg Am 86: 455-464.

Koga H, Shimaya M, Muneta T, Nimura A, Morito T, Hayashi M, Suzuki S, Ju YJ, Mochizuki T, Sekiya I (2008) Local adherent technique for transplanting mesenchymal stem cells as a potential treatment of cartilage defect. Arthritis Res Ther 10: R84.

Koga H, Engebretsen L, Brinchmann JE, Muneta T, Sekiya I (2009) Mesenchymal stem cell-based therapy for cartilage repair: a review. Knee Surg Sports Traumatol Arthrosc 17: 1289-1297.

Kumar P, Oka M, Toguchida J, Kobayashi M, Uchida E, Nakamura T, Tanaka K (2001) Role of uppermost superficial layer of articular cartilage in the lubrication mechanism of joints, J Anat 199: 241-250.

Lee OK, Kuo TK, Chen WM, Lee KD, Hsieh SL, Chen TH (2003) Isolation of multipotent mesenchymal stem cells from umbilical cord blood. Blood 103: 1669-1675.

MacConaill MA (1951) The movements of bones and joints; the mechanical structure of articulating cartilage. J Bone Joint Surg Br 33: 251-257.

Mansour JM, Mow VC (1976) The permeability of articular cartilage under compressive strain and at high pressures. J Bone Joint Surg Am 58: 509-516. 
Maroudas A, Bullough P, Swanson SA, Freeman MA (1968) The permeability of articular cartilage. J Bone Joint Surg Br 50: 166-177.

Mow VC, Fithian DC, Kelly MA (1990) Fundamentals of articular cartilage and meniscus biomechanics. In: Articular Cartilage and Knee Joint Function: Basic Science and Arthroscopy (Ewing JW, ed), Raven Press, New York, pp 1-18.

Muir H, Bullough P, Maroudas A (1970) The distribution of collagen in human articular cartilage with some of its physiological implications. J Bone Joint Surg Br 52: 554-563.

Nansai R, Suzuki T, Shimomura K, Ando W, Nakamura N, Fujie H (2011) Surface morphology and stiffness of cartilage-like tissue repaired with a scaffold-free tissue engineered construct. J Biomech Sci Eng6: 40-48.

Nejadnik H, Hui JH, Feng Choong EP, Tai BC, Lee EH (2010) Autologous bone marrow-derived mesenchymal stem cells versus autologous chondrocyte implantation: an observational cohort study. Am J Sports Med 38: 11101116.

O’Driscoll SW, Keeley FW, Salter RB (1988) Durability of regenerated articular cartilage produced by free autogenous periosteal grafts in major full-thickness defects in joint surfaces under the influence of continuous passive motion. A follow-up report at one year. J Bone Joint Surg Am 70: 595-606.

Pickard JE, Fisher J, Ingham E, Egan J (1998) Investigation into the effects of proteins and lipids on the frictional properties of articular cartilage. Biomaterials 19: 1807-1812.

Pittenger MF, Mackay AM, Beck SC, Jaiswal RK, Douglas R, Mosca JD, Moorman MA, Simonetti DW, Craig S, Marshak DR (1999) Multilineage potential of adult human mesenchymal stem cells. Science 284: 143-147.

Rieppo J, Hyttinen MM, Halmesmaki E, Ruotsalainen H, Vasara A, Kiviranta I, Jurvelin JS, Helminen HJ (2009) Changes in spatial collagen content and collagen network architecture in porcine articular cartilage during growth and maturation. Osteoarthritis Cartilage 17: 448-455.

Sakaguchi Y, Sekiya I, Yagishita K, Muneta T (2005) Comparison of human stem cells derived from various mesenchymal tissues: superiority of synovium as a cell source. Arthritis Rheum 52: 2521-2529.

Saris DB, Vanlauwe J, Victor J, Haspl M, Bohnsack M, Fortems Y, Vandekerckhove B, Almqvist KF, Claes T, Handelberg F, Lagae K, Van der Blauwhede J, Vandenneucker H, Yang KG, Jelic M, Verdonk R (2008) Characterized chondrocyte implantation results in better structural repair when treating symptomatic cartilage defects of the knee in a randomized controlled trial versus microfracture. Am J Sports Med 36: 235-246.

Schmidt TA, Plaas AH, Sandy JD (2009) Disulfidebonded multimers of proteoglycan 4 PRG4 are present in normal synovial fluids. Biochim Biophys Acta 1790: 375-384.

Shimomura K, Ando W, Tateishi K, Nansai R, Fujie H, Hart DA, Kohda H, Kita K, Kanamoto T, Mae T, Nakata K, Shino K, Yoshikawa H, Nakamura N (2010) The influence of skeletal maturity on allogenic synovial mesenchymal stem cell-based repair of cartilage in a large animal model. Biomaterials 31: 8004-8011.

Stolz M, Raiteri R, Daniels AU, VanLandingham MR, Baschong W, Aebi U (2004) Dynamic elastic modulus of porcine articular cartilage determined at two different levels of tissue organization by indentation-type atomic force microscopy. Biophys J 86: 3269-3283.

Swann DA, Sotman S, Dixon M, Brooks C (1977) The isolation and partial characterization of the major glycoprotein (LGP-I) from the articular lubricating fraction from bovine synovial fluid. Biochem J 161: 473-485.

Teshima R, Otsuka T, Takasu N, Yamagata N, Yamamoto K (1995) Structure of the most superficial layer of articular cartilage. J Bone Joint Surg Br 77: 460-464.

Thambyah A, Broom N (2007) On how degeneration influences load-bearing in the cartilage-bone system: a microstructural and micromechanical study. Osteoarthritis Cartilage 15: 1410-1423.

Weiss JA, Maakestad BJ (2006) Permeability of human medial collateral ligament in compression transverse to the collagen fiber direction. J Biomech 39: 276-83.

Wickham MQ, Erickson GR, Gimble JM, Vail TP, Guilak F (2003) Multipotent stromal cells derived from the infrapatellar fat pad of the knee. Clin Orthop 412: 196-212.

\section{Discussion with Reviewers}

Reviewer I: The presence and function of a distinct lamina splendens layer has been a somewhat controversial topic within the field of cartilage research. Here you suggest that this layer could be important for establishing the permeability and, thereby, the viscoelastic properties of the repair tissue. Does the literature suggest what sort of starting material might be placed in the defect to reconstitute the lamina splendens? Alternatively, do you think it would be feasible to reproduce this thin, acellular material in vitro and "coat" it onto a freshly-filled defect as a means to improve the immediate functionality of the repair?

Authors: As far as we can ascertain, there are unfortunately no reports in the available literature which address the reconstruction of the lamina splendens itself. Hollander $e t$ al. (2010; text reference) also emphasised the importance of regeneration of the lamina splendens at the joint surface. However, it may be a significant challenge to restore the integrity of the lamina splendens and future innovative studies are certainly needed to solve this problem. The suggestion of reproducing a thin, acellular material in vitro and "coating" it onto a freshly-filled defect is very interesting and worth trying for the immediate functional repair.

Reviewer II: This study follows on from previous studies conducted by this group, namely; Ando et al. (2007), Ando et al. (2008), Katakai et al. (2009) and Shimomura et al. (2010) (text references). These studies have explored the various properties of TEC derived from synovial mesenchymal stem cells in relation to biomechanics, tissue maturity, cartilage repair and chondrogenicity. Figures 1, 
3 and 4 have appeared in subtly different forms in earlier manuscripts and essentially duplicate the results seen in these earlier manuscripts. The results of the macro-scale tangent modules (Fig. 3d) between Normal and TEC cartilage were reported in Fig. 5 of Ando et al. (2007), and the results of frictional coefficient also reported in the same Figure in the same manuscript for essentially the same experiment with different parameters. Please comment.

Reviewer V: Outcomes of a similar experiment were already reported in Ando et al. (2007), and are hence not real "novel" data. Similar data as presented in Fig. 3 was reported previously, as well (is Fig. 3D not based on the same data as Fig. 6B in Katakai et al., 2009?). Please comment.

Authors: We used the same immature animals as in the previous studies of Ando et al. (2007) and Katakai et al. (2009) (text references). However, we have performed more detailed and different analysis, namely histological and micro-scaled biomechanical analysis of the surface structure of the repair cartilage. Although there are some similar data observed, analogous to the previous studies, such data have been used as the introduction of the new investigations conducted in the present study. Furthermore, even with regard to the somewhat similar data, the detailed experimental conditions of the mechanical analysis were quite different from the previous studies. The histological figures also have been obtained from different areas of the samples, something not done previously. Therefore, all data in this paper are not the simple reuse of those from the previous studies. We believe the inclusion of these data helps the readers to clearly understand the whole story of the present study (and why we focused on the analysis of details of the superficial structure).

Reviewer II: As PRG4 is a secreted protein most of antibody labelling is extracellular, therefore we are not able to observe if cells in the TEC are producing this protein. Following on from the latter point, it is well known that PRG4 from the synovium or surrounding cartilage that is secreted into the synovial fluid can be deposited onto surrounding (TEC) cartilage. Therefore, the presence of antibody labelling in TEC cartilage does not reveal anything conclusive about cellular production of PRG4 by differentiated MSCs in TEC cartilage. The authors' analysis of these observations is insufficient. Please comment.

Authors: Since the localisation of PRG4 (Lubricin) has been considered to be related to its tissue lubrication property, we investigated the localisation of PRG4 by immunohistochemical analysis as a potential indicator of tissue surface lubrication integrity. PRG4 was localised at the surface layer of normal cartilage, as well as the TECmediated repair cartilage. On the other hand, the purpose of PRG4 staining was not to detect the cellular source of the PRG4 but to assess the localisation of the PRG4 molecule at the superficial zone of repair tissue, which might be related to lubrication at the tissue surface. Therefore, we have decided not to add further analysis regarding the localisation of the cellular production of PRG4 (e.g., by in situ hybridisation) in the present study.
Reviewer III: The permeability of cartilage is known to be strain-dependant. The authors compressed their samples by $30 \%$ prior to permeability testing. Please clarify the motivation for this.

Authors: To avoid leaking water, it was required to tighten the water pipe to the cartilage surface in the experiment. Therefore, the permeability test was performed at the compressive strain of $30 \%$. Using the equation for Darcy's law indicated in the text, it is possible to calculate the permeability at any strain.

Reviewer III: The micro-indentation testing revealed differences in the surface properties of normal and engineering tissues. This was not extended to testing deeper regions of the tissue. Would this be possible? Such analysis may reveal more subtitle difference in the mechanics of other regions of the repair tissue.

Authors: Unfortunately, we did not perform such an AFM measurement on the tissue although it should be possible to do in the future. In the future, we would like to perform the AFM measurement on each layer of uninjured cartilage and the repair tissue.

Reviewer IV: The authors describe positive staining for PRG4 to be in the surface (Fig. 7a). There appears to be some staining in/of the cells lower in the cartilage also, at least in the image from the untreated group. Do the authors have any comment on this?

Authors: The positive staining of PRG4 was observed in the image of the untreated defect group. It is well known that synovial cells synthesise PRG4 (Schumacher et al., 1999, additional reference). We speculated that this fibrous tissue in the untreated group might have been developed by cells from the surrounding synovial tissues and thus express the PRG4. With this speculation, there may have been some positive staining detected in the deeper area due to infiltration of the defect by such cells.

Reviewer IV: How relevant do the authors think that an injury model in a 4 month old pig is to the reparative capacity of mature and ageing humans with degenerative musculoskeletal conditions?

Authors: We have previously confirmed the feasibility of the TEC to facilitate cartilage repair regardless of skeletal maturity (Shimomura et al., 2010, text reference). Therefore, the factor of aging (maturity) could be of negligible influence on the outcome of treatment. In other words, the use of immature animal has been validated to have clinical relevance. We have currently no evidence regarding the effect of potential degenerative conditions on repair using a TEC approach. Clearly osteoarthritis is an inflammatory condition, so the point is relevant but answers must await results of future investigations.

Reviewer V: Can the shape and size of the TEC be controlled? This might be a necessary requirement for future application.

Authors: The size of the TECs can be controlled by changing the size of the culture dishes to be used and 
cell number to be inoculated. Thus, we chose the most suitable size of culture dish for the present studies, as well as prepared the required number of cells based on the estimated volume of the cartilage lesions/defects which is measured macroscopically, arthroscopically, or by MRI before implantation surgery. Details can be found in Ando et al. (2007) and Ando et al. (2008) (text references).

Reviewer V: Why were the TECs prepared as allografts without chondrogenic stimulation? If the allografts were stimulated chondrogenically, would there still be such a difference in the biomechanical stability of the superficial layer?

Authors: We are currently investigating the implantation of the TEC with stimulation by relevant growth factors. We are interested in the potential improvement of the superficial zone by any biological manipulation of the TEC prior to or concurrent at the time of implantation. Hopefully, we will be able to report the results of such studies in the not so distant future.

Reviewer V: It would actually be quite interesting to also test the edges of the specimens, rather than only the centre for biomechanical stability, especially as this can be hugely important in preventing graft failure.

Authors: We have recently completed measurement of the integration strength of the implants, and the results are in preparation for a future submission. Interestingly, we have found that the integration strength also depends on the depth (deep lesion shows the highest strength and superficial shows the lowest value). However, some details remain to be confirmed, but we hope to be able to report the results in the near future.

Reviewer V: The introduction of depth dependent differences may well be very important for the successful long term performance of regenerative implants. Other cell sources, such as chondrocytes or bone marrow derived stem cells may, based on recent findings in the literature, be (more) suitable. Have the authors any experience with these in their model and/or could they hypothesise how these cells would be have in their approach?

Authors: The reason for the use of synovial MSCs is based on the reported characteristics of synovial MSCs such as the retention of multipotent differentiation potential over many passages of culture (De Bari et al., 2001, text reference) and superior chondrogenic potential among MSCs derived from many tissues (Sakaguchi et al., 2005, text reference). We have not had any experience with MSCs derived from other tissues; however, based on the cellular characteristics, we believe that the synovium could be one of the most suitable cell sources for cartilage regeneration therapies.

Reviewer VI: Can you explain the large degree of variability in the quasi-static compression testing, as reflected by the high coefficients of variance (=SD/mean)? Is such inter-sample variability typical for this sort of test? Authors: Since the edge of the AFM probe is nano-scale and the indentation depth is less than micro-scale, the results of the indentation test are site-specific. Therefore, it is likely that the variability in the surface condition of tissue samples could potentially have led to the somewhat high inter-sample variability in the test. Perhaps with further time post-implantation some of this variability may disappear, but currently it is the "state of the art".

\section{Additional Reference}

Schumacher BL, Hughes CE, Kuettner KE, Caterson B, Aydelotte MB (1999) Immunodetection and partial cDNA sequence of the proteoglycan, superficial zone protein, synthesized by cells lining synovial joints. J Orthop Res 17: $110-120$. 